\title{
Composite Materials for Adsorption-Catalytic Purification of Toxic Organic Impurities
}

\author{
Kusman Dossumov, Mikhail Nauryzbayev, Dina Churina, Sergey Efremov, Bulat Kenessov and Moldir Telbayeva \\ Center of Physical-Chemical Methods of Investigations and Analysis, al-Farabi Kazakh National University, Almaty 050012, \\ Kazakhstan
}

Received: November 25, 2014 / Accepted: January 5, 2015 / Published: March 31, 2015.

\begin{abstract}
Design of high effective catalysts with unique properties opens good perspectives for solving environmental problems of cleaning waste gas, particularly from toxic impurities of organic solvents. A new thermostable nanostructured composite materials based on shungyte was obtained and determined their adsorption capacity on the model substance o-xylene. Xylene used as a model substance is a part of the organic solvent presents in waste industrial gases. Best xylene sorbents (449.7 mg/g) —activated shungyte containing $70 \%$ carbon and saksaul charcoal $(554.3 \mathrm{mg} / \mathrm{g})$. Then polyoxide catalysts on the base of transition metals $(\mathrm{Ni}, \mathrm{Mn}, \mathrm{Cu})$ modified by the rare earth elements ( $\mathrm{La}, \mathrm{Ce}$ and $\mathrm{Nd}$ ), supported on a granular carrier were studied in the reaction of deep oxidation of o-xylene. $100 \%$ activity showed $7.0 \% \mathrm{Cu}$-Mn-Ce-catalyst at $T: 250-300{ }^{\circ} \mathrm{C}, C_{x y l e n e}: 0.6 \mathrm{~g} / \mathrm{m}^{3}$, the optimum space velocity of gas $-1,200 \mathrm{~h}^{-1}$ for catalysts supported on a granular carrier. The results obtained can be used in the purification of waste gas from paint, furniture, cable, printing and other enterprises from the impurities of toxic organic solvents.
\end{abstract}

Key words: Composite material, adsorption, xylene, catalyst, sorbent, shungyte.

\section{Introduction}

At the moment, when the waste recycling enterprises fully yet, the main task of gas cleaning is bringing the toxic impurities in the flue gas to the minimum permissible concentrations established sanitary standards. Industrial gases are usually contaminated with harmful impurities, so more and more attention is paid to research on cleaning and disposal of traces of organic solvents in the exhaust gas [1-5]. Of thermal, catalytic and adsorption methods of neutralization adsorption-catalytic method is promising due to the high efficiency of purification from impurities and can be cleaned with large amounts of gases containing a small fraction of impurities.

The aim of the work was the development of new composite materials for directional adsorption-catalytic purification of industrial waste gas from impurities of toxic organic solvents. Adsorption-catalytic method of

Corresponding author: Dina Churina, Ph.D., research fields: catalysis and ecology. E-mail: dina.churina@gmail.com. purifying toxic exhaust gases from organic impurities [6] based on the implementation of a cyclic treatment process in two successive stages. In the first stage of the cycle, occurs prior accumulation due to adsorption and/or chemisorption of a toxic impurity in existing gas in the catalyst bed. The second cycle step is oxidation of toxic impurities adsorbed in the catalyst layer, which occurs when passing air through the catalyst layer heated to a temperature above the characteristic temperature of the onset of deep oxidation of adsorbed impurities. This method provides a high degree of purification of exhaust gases with low initial concentrations of impurities, thus, it is substantially less energy compared with the other. Purified gas can be returned to the system if the impurity concentration is significant. The combination of these two purification steps of the organic impurities was used in this study.

\section{Experiments}

This article is a continuation of a series of studies $[7,8]$ 
devoted to the development of highly efficient adsorbents-catalysts for the two-step adsorption-catalytic purification of industrial waste gas from impurities of organic solvents. Previously performed experimental studies to obtain composite materials based on carbon shungytes and saksaul coal and heat treated with subsequent activation of the vapor-gas mixture, allowing developing a large specific surface.

This paper describes following composite materials - shungyte and activated carbon based on the chips of saksaul studied for their adsorption capacity of the model substance-o-xylene. In the second step, proposed polyoxide catalysts supported on carriers for the deep oxidation of the adsorbed organic substances.

\subsection{Synthesis of Composite Materials for the} Adsorption of Xylene

Shungytes-specific carbonaceous rocks. Their constituent carbon with a metastable amorphous molecular structure, not prone to graphitization. The main element of the supramolecular structure is shungyte carbon globule-multilayer formation of sizes up to $10 \mathrm{~nm}$ with pore inside. Shungyte is a black, mineral shiny with conchoidal glass fracture, brittle. Shungyte rocks vary in chemical and mineralogical composition and, as a consequence, have different adsorption and catalytic properties. They represent a natural composite - $\mathrm{a}$ uniform distribution of fine crystalline silica particles in an amorphous carbon matrix. Various samples of activated shungyte with carbon content of $25.0 \%, 45.0 \%$ and $70.0 \%$, and saksaul charcoal were prepared according to the developed technique, comprising the steps of froth flotation and treatment with acid. As a result, the samples prepared with the following content of carbon and the particle size:

- shungyte with $25.00 \%$ carbon, the particle size of minus 74 microns;

- concentrate with a percentage of carbon $45.00 \%$ and a particle size of minus 40 microns;

- concentrate with a percentage of $70.00 \%$ carbon and tails, a particle size of minus 40 microns.

There were studied the effects of temperature, space velocity and the concentration of o-xylene in the reaction mixture on the adsorption capacity of the composite materials on the basis of shungyte with activated carbon of different content and saksaul coal on the pilot installation consisting of a compressor (Parker Balston, Denmark), zero clean air generator (Parker Balston, Denmark), a pressure regulator (Swagelok, USA) syringe pump KDS 100 (KD Scientific, USA), $250 \mathrm{~mL}$ calibrated bulb for averaging the flask analyte concentration with teflon valves and sampling port (Supelco, USA) and a modified sampling vial (CTC Analytics AG, Switzerland) connected to the inlet of the calibrated bubble flowmeter. Analyzed samples were taken from $20 \mathrm{~mL}$ vial using Combi-PAL (CTC Analytics AG, Switzerland) autosampler mounted on a gas chromatograph with mass spectrometric detector 7890A/5975C (Agilent, USA).

Before the test, sorbents are dried at $200{ }^{\circ} \mathrm{C}$ for $3 \mathrm{~h}$. Determination of the adsorption capacity of the adsorbent was carried out by passing through it a mixture of air with xylene and measuring the xylene concentration in the outlet stream after the adsorbent. The experiment was carried out over a period of time required for the saturation of the adsorbent and the equilibrium in the system.

\subsection{Design of Catalysts with Different Active Phase Supported on a Granular Carrier}

Design of catalysts with different active phase based on the oxides of nickel, manganese, copper and their binary mixtures, as well as the modification by the rare earth elements was carried out when supported on the granular carriers. Preparation of granular catalysts was carried out by capillary impregnation of the support for water capacity.

Oxidative conversion of model substance- $\mathrm{o}$-xylene with atmospheric oxygen was investigated in the flow catalytic laboratory facility over the catalysts supported 
on a granular carrier in the temperature range 350-600 ${ }^{\circ} \mathrm{C}$, with space velocities 400-1,200 $\mathrm{h}^{-1}$ and atmospheric pressure. Ratio xylene: air varied from $6: 3$ to $3: 3$. The volume of catalyst supported on the granular carrier was $2 \mathrm{~cm}^{3}$. Installation consists of a reactor, heating system, mixer and instrumentation. Air is supplied from a balloon, and xylene with a metering pump in a rheometer and then to the mixer, where upon the mixture of xylene with air fed to the reactor with the catalyst. The temperature was measured in the catalyst layer using a chromel-alumel thermocouple on the device KSP-3. Sampling was made before and after the catalyst. Analysis of xylene and its deep oxidation products was performed on a GC chromatograph Hromas GH-1000, issue 2012.

\section{Results and Discussion}

\subsection{Investigation of the Adsorption Capacity of Sorbents}

Figs. 1 and 2 show typical curves of the output o-xylene adsorption for sorbents. The adsorption capacity of the sorbent was calculated on the basis of observed peaks considering the sensitivity factor. Results obtained on adsorption capacities are shown in Table 1, from which it follows that as the shungyte carbon content increase from $11 \%$ to $23 \%$, its adsorption capacity is increased from $18.0 \mathrm{mg}$ to $41.0 \mathrm{mg}$ of xylene per gram $(\mathrm{mg} / \mathrm{g})$ of shungyte. With increasing of carbon content in shungyte to $50 \%$ and $70 \%$, its adsorption capacity reaches $261.6 \mathrm{mg} / \mathrm{g}$ and $449.7 \mathrm{mg} / \mathrm{g}$, respectively. Maximum equilibrium capacity $(554.3 \mathrm{mg} / \mathrm{g})$ was found for the saksaul coal. The values of the equilibrium capacity arranged depending on the percentage of carbon in the series: saksaul coal $>70 \%>50 \%>23 \%>11 \%>4 \%$. Further investigation of the influence of the space velocity, temperature and concentration of o-xylene in the reaction mixture on the adsorption capacity of the composite materials was carried out on the basis of shungyte with activated carbon $70 \%$. Decrease in the space velocity from $12,000 \mathrm{~h}^{-1}$ to $5,000 \mathrm{~h}^{-1}$ increases the protective effect from $40 \mathrm{~min}$ to $185 \mathrm{~min}$. However,

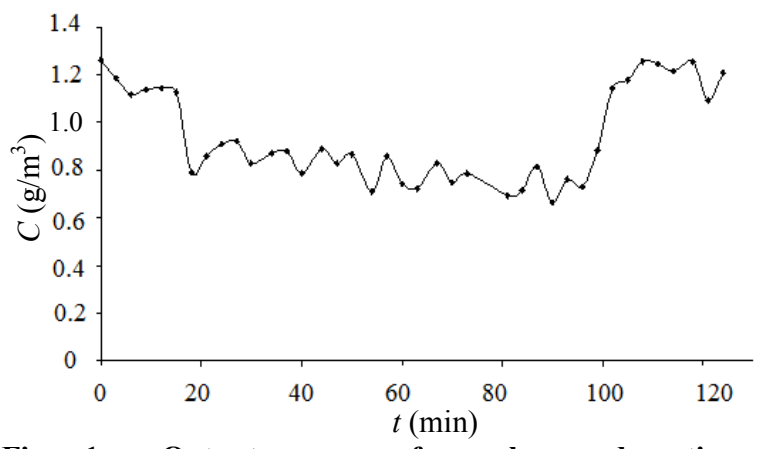

Fig. 1 Output curve of o-xylene adsorption by sorbent-shungyte containing $11 \%$ carbon.

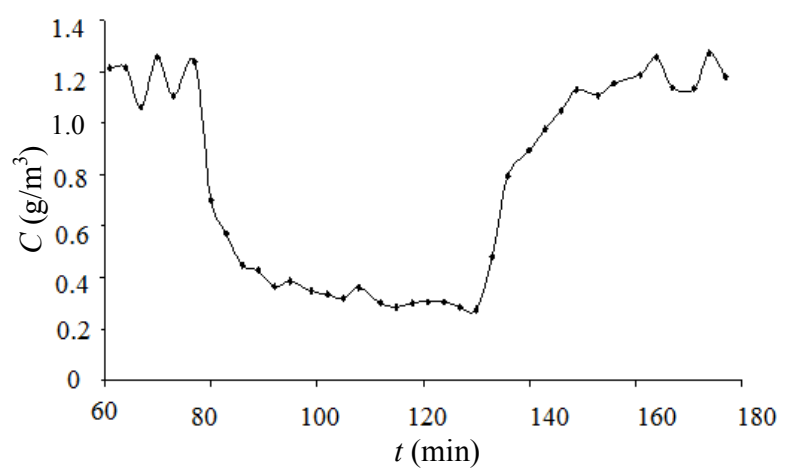

Fig. 2 Output curve of 0 -xylene adsorption by sorbent-shungyte containing $23 \%$ carbon.

Table 1 The adsorption capacity of studied sorbents on o-xylene.

\begin{tabular}{ll}
\hline Sorbent & $\begin{array}{l}\text { The adsorption capacity of } \\
\text { sorbents }(\mathrm{mg} / \mathrm{g})\end{array}$ \\
\hline Shungyte, 4\% carbon & 0.1 \\
Shungyte, 11\% carbon & 18.0 \\
Shungyte, 23\% carbon & 41.0 \\
Shungyte, 50\% carbon & 261.6 \\
Shungyte, 70\% carbon & 449.7 \\
Saksaul coal & 554.3 \\
\hline
\end{tabular}

the size of the equilibrium adsorption capacity in all these conditions remained constant at $449.7 \mathrm{mg} / \mathrm{g}$ sorbent. At the space velocity of $5,000 \mathrm{~h}^{-1}$ o-xylene adsorption, tests were carried out at elevated temperatures from $20{ }^{\circ} \mathrm{C}$ to $200{ }^{\circ} \mathrm{C}$. It was found that increasing the temperature to $100{ }^{\circ} \mathrm{C}$ sharply reduces the adsorption capacity of activated shungyte to $44.9 \mathrm{mg} / \mathrm{g}$. At $200{ }^{\circ} \mathrm{C}$, xylene adsorption does not occur.

The study of the dynamics of the adsorption of o-xylene from air mixture showed that increasing the concentration of xylene in the reaction mixture from $300 \mathrm{mg} / \mathrm{m}^{3}$ to $500 \mathrm{mg} / \mathrm{m}^{3}$ reduces saturation time 
shungyte by xylene on 1.7 times while maintaining the equilibrium adsorption capacity of the activated shungyte with carbon content $70 \%$. Thus, the adsorption capacity of composite materials on xylene by shungyte with different carbon contents is defined. It has been established that the best of xylene sorbent is activated shungyte sample containing of $70 \%$ carbon $(449.7 \mathrm{mg} / \mathrm{g})$. The maximum value of this characteristic $(554.3 \mathrm{mg} / \mathrm{g})$ was obtained by using saksaul coal.

\subsection{Studying of the Activity of the Catalysts}

The first step was to prepare and test of mono oxide catalysts: Ni-, $\mathrm{Cu}-$ and $\mathrm{Mn}$. Further, there were prepared and studied binary oxide catalysts: $\mathrm{Ni}-\mathrm{Cu}$, $\mathrm{Cu}-\mathrm{Mn}$ and $\mathrm{Mn}-\mathrm{Ni}$. The next step of varying the composition of the active phase of the catalyst was modification of the best binary oxide catalyst by the rare earth metals - cerium, lanthanum and neodymium.

Following are the results of the test of the catalysts as the complexity of their composition in the complete oxidation of a model substance- $\mathrm{o}$-xylene by air oxygen. To determine the effect of the active phase on the direction of the oxidation reaction of o-xylene were first tested mono oxide catalysts: $\mathrm{Ni}-, \mathrm{Cu}-$ and $\mathrm{Mn}-$, supported on a granular carrier. Their activity was determined in the complete oxidation of o-xylene under the conditions: $T-300{ }^{\circ} \mathrm{C}$, the space velocity of oxygen $-1,200 \mathrm{~h}^{-1}$, the catalyst volume is $2 \mathrm{~mL}$.

As can be seen from Table 2, among the investigated monoxides of nickel, copper and manganese, the best activity showed the copper catalyst whose activity in complete oxidation of o-xylene was $83 \%$, while for the nickel catalyst $69 \%$ and manganese $78 \%$. Next, under the same conditions were studied binary oxide catalysts: $\mathrm{Ni}-\mathrm{Cu}, \mathrm{Cu}-\mathrm{Mn}$ and $\mathrm{Mn}-\mathrm{Ni}$. Among them, the highest activity (98\%) is typical for Cu-Mn. Activity of $\mathrm{Ni}-\mathrm{Cu}$ $87 \%$, and the $\mathrm{Mn}-\mathrm{Ni}$ 91\%. Catalyst $\mathrm{Cu}-\mathrm{Mn}$, which showed the highest activity was modified with oxides of REE (rare earth elements): cerium, lanthanum and neodymium. One hundred percent of xylene oxidation is observed in all studied (Cu-Mn-Ce, Cu-Mn-La and
Table 2 Comparative activity of supported catalysts to a granular carrier of complete oxidation of o-xylene.

\begin{tabular}{ll}
\hline Catalysts & Activity (\%) \\
\hline $\mathrm{Ni}$ & 69 \\
$\mathrm{Cu}$ & 83 \\
$\mathrm{Mn}$ & 78 \\
$\mathrm{Ni}-\mathrm{Cu}$ & 87 \\
$\mathrm{Cu}-\mathrm{Mn}$ & 98 \\
$\mathrm{Mn}-\mathrm{Ni}$ & 91 \\
$\mathrm{Cu}-\mathrm{Mn}-\mathrm{Ce}$ & 100 \\
$\mathrm{Cu}-\mathrm{Mn}-\mathrm{La}$ & 100 \\
$\mathrm{Cy}-\mathrm{Mn}-\mathrm{Nd}$ & 100 \\
\hline
\end{tabular}

Cu-Mn-Nd) catalysts at $300{ }^{\circ} \mathrm{C}$ (Table 2).

However, when $250{ }^{\circ} \mathrm{C}$ oxidation of o-xylene $5.6 \%$ (Fig. 3) above for $\mathrm{Cu}-\mathrm{Mn}-\mathrm{Ce}-\mathrm{catalyst}$ than $\mathrm{Cu}-\mathrm{Mn}-\mathrm{La}$ and $\mathrm{Cu}-\mathrm{Mn}-\mathrm{Nd}$.

Thus, among the new synthesized oxide catalysts based on transition and rare earth metals $\mathrm{Cu}-\mathrm{Mn}-\mathrm{La}$, $\mathrm{Cu}-\mathrm{Mn}-\mathrm{Ce}$ and $\mathrm{Cu}-\mathrm{Mn}-\mathrm{Nd}$, the highest activity showed $\mathrm{Cu}-\mathrm{Mn}-\mathrm{Ce}-\mathrm{catalyst}$.

3.3 Investigation of the Influence of Process Parameters on the Activity of Deep Oxidation of Xylene by Atmospheric Oxygen

Activity of prepared Cu-Mn-La, Cu-Mn-Ce and $\mathrm{Cu}-\mathrm{Mn}-\mathrm{Nd}$ - supported on a granular carriers catalyst were studied in the reaction of deep oxidation of o-xylene by atmospheric oxygen to $\mathrm{CO}_{2}$ and $\mathrm{H}_{2} \mathrm{O}$ with varying of process parameters: temperature, space velocity and ratio of the reaction medium. Temperature of the process being studied at the range from $100{ }^{\circ} \mathrm{C}$ to $300{ }^{\circ} \mathrm{C}$, and was as follows: $100{ }^{\circ} \mathrm{C}$, $150{ }^{\circ} \mathrm{C}, 200{ }^{\circ} \mathrm{C}, 250{ }^{\circ} \mathrm{C}, 300{ }^{\circ} \mathrm{C}$. Fig. 3 shows the activity of $\mathrm{Cu}-\mathrm{Mn}-\mathrm{La}, \mathrm{Cu}-\mathrm{Mn}-\mathrm{Ce}$ and $\mathrm{Cu}-\mathrm{Mn}-\mathrm{Nd}$ catalysts supported on granular carrier on the temperature of the reaction.

Most active at all temperatures studied characteristic for the $\mathrm{Cu}-\mathrm{Mn}$-Ce-catalyst and at $150{ }^{\circ} \mathrm{C}$, it is $41 \%$, with an increase in temperature to $50{ }^{\circ} \mathrm{C}$ activity increased to $83 \%$ and at $250{ }^{\circ} \mathrm{C}$ and $300{ }^{\circ} \mathrm{C}$ activity of $\mathrm{Cu}-\mathrm{Mn}$-Ce-catalyst equal to $100 \%$, while over the $\mathrm{Cu}-\mathrm{Mn}-\mathrm{La}$ and $\mathrm{Cu}-\mathrm{Mn}-\mathrm{Nd}$ catalysts oxidation at $250{ }^{\circ} \mathrm{C}$ reaches $94 \%$ and $95 \%$, respectively. 


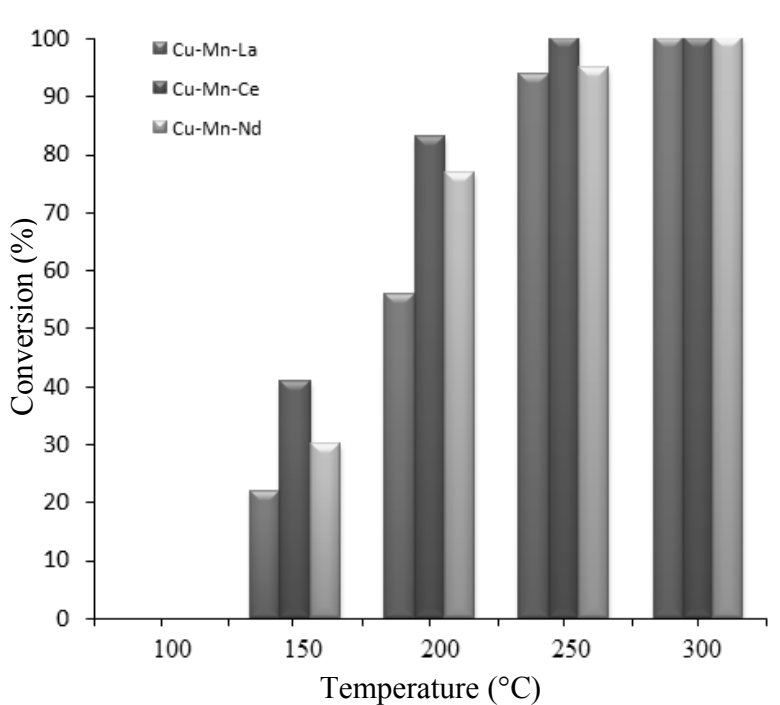

Fig. 3 The dependence of the catalyst activity on the temperature.

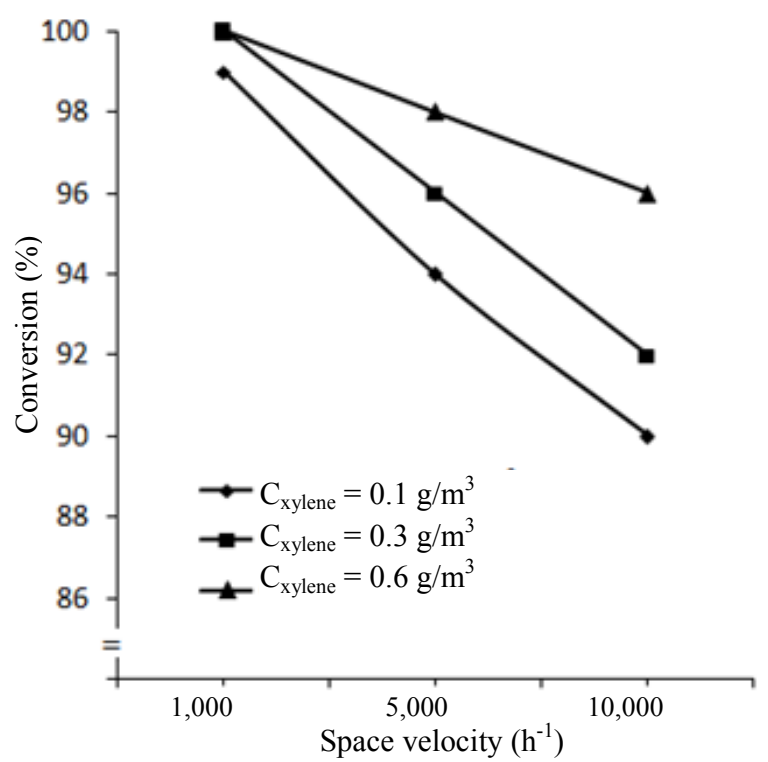

Fig. 4 Dependence of $\mathrm{Cu}-\mathrm{Mn}$-Ce-catalyst activity on the concentration of 0 -xylene at various space velocities of the gas.

Thus, the most active among the three studied catalysts is a Cu-Mn-Ce-catalyst. Optimum temperature at which all the studied catalysts are the most active is $250-300{ }^{\circ} \mathrm{C}$. The most active $(100 \%)$ $\mathrm{Cu}-\mathrm{Mn}$ - modified by cerium catalyst at $250-300{ }^{\circ} \mathrm{C}$. Further detailed investigation of the effect of the concentration of xylene and a space velocity of the gas-air mixture on the conversion of xylene was carried out on Cu-Mn-Ce-catalyst.

It was studied the effect of the concentration of o-xylene: $0.1,0.3$ and $0.6 \mathrm{~g} / \mathrm{m}^{3}$ at gas space velocities of $1,000,5,000$ and $10,000 \mathrm{~h}^{-1}$ at a temperature of $300{ }^{\circ} \mathrm{C}$ on the activity of $\mathrm{Cu}-\mathrm{Mn}$-Ce-catalysts (Fig. 4).

Most activity of $\mathrm{Cu}-\mathrm{Mn}$-Ce-catalyst is observed in xylene concentration of $0.6 \mathrm{~g} / \mathrm{m}^{3}$ at all gas space velocities as compared to the concentrations of xylene $0.3 \mathrm{~g} / \mathrm{m}^{3}$ and $0.1 \mathrm{~g} / \mathrm{m}^{3}$. However, at concentrations of xylene $0.1 \mathrm{~g} / \mathrm{m}^{3}$ and $0.3 \mathrm{~g} / \mathrm{m}^{3}$ at gas space velocity $1,000 \mathrm{~h}^{-1}$ activity of $\mathrm{Cu}-\mathrm{Mn}$-Ce-catalyst is high and is $99 \%$ to $100 \%$.

Thus, the optimal concentration of xylene- $-0.6 \mathrm{~g} / \mathrm{m}^{3}$ in which $\mathrm{Cu}-\mathrm{Mn}-\mathrm{Ce}$ is the most activity. Investigation of activity of the catalyst depends on a space velocity of the feed gas was carried out in the following ranges: $1,200,3,000,4,000,5,000,10,000 \mathrm{~h}^{-1}$. It is shown that, the optimal space velocity of the gas which is manifested in the maximum activity of $\mathrm{Cu}-\mathrm{Mn}$-Ce-catalyst for the whole studied temperature range $\left(100-350{ }^{\circ} \mathrm{C}\right)$ is $1,200 \mathrm{~h}^{-1}$.

\section{Conclusions}

Adsorption of o-xylene by shungytes with different carbon contents was studied and it showed that the best of xylene sorbent among the activated shungytes is sample $(449.7 \mathrm{mg} / \mathrm{g})$ with $70 \%$ carbon. The maximum adsorption capacity of xylene $(554.3 \mathrm{mg} / \mathrm{g})$ is observed at saksaul charcoal.

New oxide catalysts are developed and prepared on granular carrier with desired properties based on transition and rare earth metals $(\mathrm{Ni}, \mathrm{Mn}, \mathrm{Cu}, \mathrm{La}, \mathrm{Ce}$ and $\mathrm{Nd})$. Investigation of the influence of the active phase of the catalyst on the direction of oxidation of o-xylene showed that the most active among the investigated oxides of nickel, copper and manganese is the copper catalyst (83\%), among the two-component catalyst (98\%) - Cu-Mn. Modifying of bioxide catalysts by the rare earth elements enhances their activity.

The maximal activity $(100 \%)$ in the deep oxidation of o-xylene with atmospheric oxygen showed $\mathrm{Cu}-\mathrm{Mn}$-catalyst modified by cerium, containing sum of metals $-7.0 \%$. 
The influence of process parameters on the activity of optimal Cu-Mn-Ce-catalyst was defined. Maximum activity of all the catalysts examined is shown at 250-300 ${ }^{\circ} \mathrm{C}$, the optimal concentration of xylene $-0.6 \mathrm{~g} / \mathrm{m}^{3}$ and the optimum gas space velocity in the entire investigated temperature range $\left(100-350{ }^{\circ} \mathrm{C}\right)-1,200 \mathrm{~h}^{-1}$ for catalysts supported on a granular carrier.

The results obtained can be used in the adsorption-catalytic cleaning of industrial waste gas from impurities of toxic organic solvents.

Work performed by the grant of the Ministry of Education and Science of the Republic of Kazakhstan.

\section{References}

[1] Ming-Yen, W., Wen-Yi, Y., Hsing-Chung, H., and Jyh-Cherng, C. 2002. "Catalytic Oxidation of Organic Compounds in Incineration Flue Gas by a Commercial Palladium Catalyst." Journal of the Air \& Waste Management Association 52 (February): 198-207.

[2] Fairren-Jimrenez, D., Carrasco-Marrın, F., and Moreno-Castilla, C. 2007. "Adsorption of Benzene, Toluene and Xylenes on Monolithic Carbon Aerogels from Dry Air Flows." American Chemical Society, Langmuir 23 (August): 10095-101.

[3] Lorimier, C., Subrenat, A., Le Coq, L., and Le Cloirec, P. 2005. :Adsorption of Toluene onto Activated Carbonfibre Cloths and Felts: Application to Indoorair Treatment."
Environmental Technology 26 (2005): 1217-30.

[4] Lebiguea, C. J., Andriantsiferana, C., Krou, N'G., Ayral, C., Mohamed, E., Wilhelmay, A-M., Delmas, H., Le Coq, L., Gerente, C., Smith, K. M., Pullket, S., Fowler, G. D., and Graham, N. J. D. 2010. "Application of Sludge-Based Carbonaceous Materials in a Hybrid Water Treatment Process Based on Adsorption and Catalytic Wet Air Oxidation." Journal of Environmental Management 9 (2010): 2432-9.

[5] Chiang, H. L., Huang, C. P., Chiang, P. C., and You, J. H. 1999. "Effect of Metal Additives on the Physico-Chemical Characteristics of Activated Carbon Exemplified by Benzene and Acetic Acid." Carbon 37 (1999): 1919-28.

[6] Zagoruiko, A. N., and Noskov, A. S. 2000. The Method for Purifying Toxic Gases from Impurities. Rus. Federation Patent 97,108,848/12; filed May 21, 1997, and issued April 20, 2000.

[7] Dossumov, K., Churina, D. H., Efremov, S. A., Suyunbaev, W., and Maylina A. B. 2013. "Composite Materials for Adsorption-Catalytic Purification of Waste Gas from Organic Solvents." In Proceedings of International Symposium Modern Problems of Higher Education and Science in the Field of Chemistry and Chemical Technology, 342-5.

[8] Dossumov, K., Churina, D. H., Telbayeva, M. M., and Suyunbaev, W. 2012. “Adsorption-Catalytic Purification of Industrial Waste Gases from Toxic Impurities." In Proceedings of the Scientific and Technical Society “Qakhaq", 29-36. 